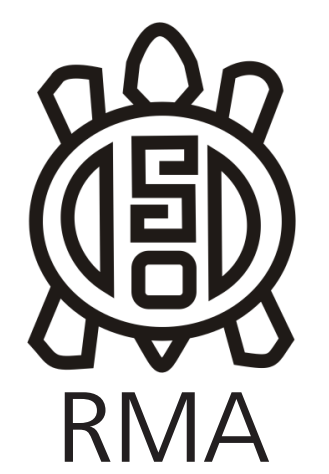

Antropología Social

\title{
Agroecologías pampeanas. Eco-lógicas instituyentes de producción local de alimentos
}

\author{
Pampean agroecologies. Instituting eco-logics of local food production
}

\author{
Romina Cravero* \\ * CIECS - CONICET, Universidad Nacional de Córdoba. \\ E-mail: romina.cravero@gmail.com
}

\begin{abstract}
Resumen
En este artículo exploramos la pregunta antropológica sobre el "cómo" se produce agroecología, que nos habilitará un desplazamiento desde la indagación por la agroecología, en singular y como un marco normativo, hacia las prácticas agroecológicas, en plural y ancladas en el hacer cotidiano de las personas. Pondremos en primer plano las experiencias de nuestros/as interlocutores para caracterizar las formas de crear y reproducir vida y trabajo rural en cuatro establecimientos de la región pampeana de la provincia de Córdoba, Argentina, intentando tanto marcar la variabilidad entre estos, así como extraer algunas premisas que constituyen a la lógica que organiza y estructura sus prácticas de producción. Identificamos que operan una agro-eco-lógica que pone en el centro las relaciones entre especies y entidades en la actividad primaria y permite poner en evidencia una co-producción de alimentos. Aquel entramado de relaciones es condición de posibilidad para que puedan resistir y existir, para crear formas de vivir y trabajar en los márgenes de la hegemonía del agronegocio. Finalmente, reflexionaremos sobre las relaciones que se establecen entre agroecología y agronegocio.
\end{abstract}

Palabras clave: Agroecología; Etnografía; Soberanía Alimentaria; Relaciones multiespecies; Agronegocio

\begin{abstract}
In this paper we explore the anthropological question about "how" agroecology is produced, which will enable us to move from the inquiry into agroecology, in the singular and as a normative framework, towards agroecological practices, in the plural and anchored in the daily activities of people. We will put in the foreground the experiences of our interlocutors to characterize the ways of create and reproduce rural life and work in four establishments in the Pampas region of the province of Córdoba, Argentina, trying to mark the variability between them, as well as to extract some premises that constitute the logic that organizes and structures its production practices. It was identified that they operate an agro-eco-logic that puts the relations between species and entities in the primary activity at the center and allows to show a co-production of food. That network of relationships is a condition of possibility so that they can resist and exist, to create ways of living and working on the margins of agribusiness hegemony. Finally, we will reflect on the relationships that are established between agroecology and agribusiness.
\end{abstract}

Keywords: Agroecology; Ethnography; Food Sovereignty; Multispecies Relations; Agribusiness

\section{Introducción}

A través del análisis etnográfico de experiencias de producción agroecológica en la región pampeana de Argentina, el presente artículo busca contribuir al conocimiento de estos procesos de transformación en el mundo rural contemporáneo.

En los últimos años, la agroecología -como forma de producción, de alimentación y sus protagonistas- ha ganado mayor visibilidad en Argentina y el mundo, en particular como alternativa al hegemónico régimen agroalimentario. De dicha visibilidad hablan tanto la especial atención que le han dado organismos internacionales (véase por ejemplo FAO, 2018) así como la multiplicación de ferias agroecológicas y la organización de compras directas entre consumidores y los y las productores en distintos territorios. También se puede mencionar la oferta cada vez más recurrente y selecta en góndolas o tiendas gourmet de productos orgánicos distinguidos como "saludables" o "naturales" aunque elitizados.

No obstante, como los y las lectores estarán anticipando, 
a pesar de su relativa visibilidad en Argentina en los últimos años, es un fenómeno de larga data. Al respecto, se pueden señalar las conferencias de Rudolf Steiner en el año 1924 sobre agricultura ecológica más conocida como "biodinámica". Más cercano en el tiempo, en las últimas décadas del siglo $X X$, algunos pioneros publicaron trabajos argumentando a favor de una forma sustentable de agricultura que denominaron "agroecología" (volveré al respecto en breve), así como comenzaron a desarrollarse experiencias de producción hoy consideradas icónicas -como son para el caso de Argentina los establecimientos Naturaleza Viva, una granja biodinámica en Santa Fe, o La Aurora, de agricultura extensiva en Buenos Aires-.

En dialogo con el vasto trabajo de agrónomos y activistas, que desde hace décadas sistematizan las bases científicas y agronómicas de este modo ecológico de producir alimentos agropecuarios y agroforestales, aquí proponemos explorar la pregunta antropológica sobre cómo se produce agroecología desde la perspectiva de las y los actores sociales. En otras palabras, el artículo recupera el material etnográfico construido durante un trabajo de campo de convivencia intensiva, realizado entre los años 2017 y 2018, para analizar cómo operan agroeco-lógicas que les permiten producir alimentos, así como vida y trabajo rural, en cuatro establecimientos de la zona pampeana de la provincia de Córdoba ${ }^{1}$. Describiremos aquí la variabilidad de experiencias y relaciones que compone aquello que denominan "agroecología" al mismo tiempo de prestar atención a cómo con sus acciones movilizan una lógica que pone en el centro de sus decisiones productivas las relaciones multiespecies en la actividad primaria. No obstante, antes de centrarme en las situaciones etnográficas, permítanme en el próximo parágrafo reponer brevemente algunas discusiones disciplinares en torno a la agroecología que fundamentan nuestra propuesta analítica.

\section{La agroecología como objeto de estudio}

La literatura que aborda la agroecología como objeto de estudio se inscribe, en su mayoría, en las Ciencias Agrarias -desarrollada principalmente por agrónomos y técnicos de instituciones que la promueven- y tiende a adoptar un enfoque de análisis normativo. Como campo de estudios es reciente y heterogéneo y, por tanto, aún se encuentran en disputa sus definiciones legítimas. No obstante, hay consenso entre sus principales referentes que se inscribe en la necesidad de un cambio del modo de producción agrícola dominante (Altieri, 2015).

Entre las décadas de los años '70 y '80 los agrónomos Stephen Gliessman (1978) y Miguel Altieri (1987) y el

\footnotetext{
1 La versión completa de este trabajo conforma una tesis de maestría en antropología de la Universidad Nacional de Córdoba que obtuvo el primer lugar en la edición 2020 del Premio Archetti organizado por el Instituto de Desarrollo Económico y Social (IDES) y, por tanto, su publicación se encuentra en prensa en la editorial Antropofagia.
}

sociólogo Eduardo Sevilla Guzmán (1993) dieron los primeros pasos para trazar las bases disciplinares de lo que se denominó "agroecología". Al respecto, vale resaltar que, si bien podemos rastrear antecedentes que trazan un camino disciplinar y esfuerzos sistemáticos por explicar y difundir "otra agricultura" diseñada en base a principios ecológicos, sus autores no dejan de señalar que estos desarrollos se producen en diálogo con tradiciones y saberes del ámbito rural.

Aunque E. Sevilla Guzmán ha sentado las bases de una perspectiva sociológica y programática de la agroecología desde España, en la que incluye a la organización social como pilar central, hasta donde conocemos, no contamos con esfuerzos similares desde las ciencias sociales en América Latina. No obstante, sí existe un importante registro y sistematización en cuanto a las dimensiones agrosistémicas y los manejos de los cultivos desde las Ciencias Agrarias (para un balance de su difusión y constitución disciplinar en Argentina véase Sarandón \& Marasas, 2015; para análisis de casos véase sobre Córdoba Barchuk et al., 2017 y Sarmiento, 2018; sobre Buenos Aires Arqueros et al., 2014; sobre Santa Fe Ottmann et al., 2013).

Para los intereses de un trabajo antropológico aquel campo de discusiones centrado en dimensiones agrosistémicas y ecológicas resultaba una referencia ineludible pero no podía agotar allí la pregunta sobre lo agroecológico, era necesario conocer lo que las personas que producen agroecológicamente hacen, cómo, con quiénes y porqué.

En contraste a las definiciones normativas de aquel campo disciplinar, al iniciar nuestra inmersión etnográfica, rápidamente nos encontramos con un heterogéneo entramado de prácticas y sentidos asociados a la agroecología. Es decir, en nuestro recorrido, lo agroecológico se presentó como un campo de prácticas y procesos ubicuo: un modo de agricultura, una disciplina científica, un movimiento social por la soberanía alimentaria, una -incipiente y en los intersticios- área de trabajo de organismos públicos como el Instituto Nacional de Tecnología Agrícola (INTA) de Argentina o de cátedras universitarias. A veces un producto de consumo elitizado y otras de producción y acceso popular. Para algunos era una forma de dejar de utilizar insumos químicos en la producción primaria. Para otros lo agroecológico era una alternativa productiva y de organización contra-hegemónica del trabajo. Cuando era definido de esta última forma por alguno de sus impulsores -agricultores, académicos, militantesaparecía revestido como una actualización de utopías emancipadoras ligado a la soberanía alimentaria y los movimientos campesinos.

Frente a aquel escenario y a los fines de una investigación antropológica era necesario abrigar aquella ubicuidad, 
que se presentaba transversal en el campo de prácticas y procesos que indagábamos, para tornarla analíticamente productiva. En las últimas décadas, la antropología y sociología rural han producido aportes sustanciales al estudio de las transformaciones en el mundo rural argentino contemporáneo que permitieron comprender la tendencia a la homogeneización en el uso de la tierra por cultivos transgénicos (Dougnac Martínez, 2016) como un proceso de agriculturización (Giarraca \& Teubal, 2008) que opera desde una lógica propia del managment moderno denominada -por críticos y promotores-como agronegocios (Gras \& Hernández, 2016) que concentró aún más la estructura productiva. No obstante, cuando iniciamos nuestra investigación en el año 2016 la agroecología era un área de aún escasa indagación en las ciencias sociales de nuestro país. Sin embargo, cabe destacar que en los últimos años se publicaron algunos trabajos de revisión conceptual y relevamiento de experiencias socioproductivas (Dominguez, 2019; Palmisano, 2018) y, además, tenemos conocimiento de, al menos, una decena de investigaciones empíricas de posgrado en curso ${ }^{2}$.

Ante la ausencia relativa de abordajes etnográficos de las experiencias agroecológicas de la segunda década del siglo XXI en la región pampeana de Argentina, las herramientas teóricas y metodológicas de la antropología de la política resultaron fundamentales para realizar el tipo de análisis propuesto. Por un lado, permitieron recuperar etnográficamente el carácter vivo y dinámico de la agroecología en tanto proceso social (Fernández Álvarez et al., 2017). Por otro lado, esta perspectiva tiene el valor de habilitar formas de indagar al ras de lo que las personas hacen sin anticipar una grilla clasificatoria. Dicho de otro modo, nos permitió llevar adelante una operación analítica orientada a no preasumir la existencia de "una" agroecología -como práctica, identidad o cosa- a fin de evitar que se tornara un elemento "sobrecodificador" (Goldman, 2015:646) de nuestros interlocutores y sus prácticas. En cambio, este tipo de abordaje nos invitó a seguir de cerca el hacer cotidiano de las personas (Quirós, 2011) que hacían agroecología.

Más que buscar definiciones taxativas sobre qué es la agroecología o identidades sustantivas de un nuevo o viejo tipo de agricultores, este artículo busca mostrar los modos específicos en que las personas producen alimentos que califican como "sanos", "orgánicos", "medicinales" o "agroecológicos". Claro está, cada una de estas formas de producir da cuenta de un repertorio de prácticas que sientan posiciones dentro de las tramas de relaciones sociales e históricas, que apuntamos a incorporar en el análisis.

2 Agradezco a Ixs evaluadorxs anónimxs todas sus observaciones que nutrieron la versión final de este escrito y en particular la mención del trabajo de G. Schiavoni (2020) que fuera publicado en simultaneo al envío de este artículo por lo cual no fue posible incorporarlo.

\section{Las agroecologías pampeanas en la hegemonía del agronegocio}

En la provincia de Córdoba -como en gran parte del territorio argentino- desde el inicio del siglo XXI la producción de commodities agrícolas a gran escala homogeneizó el paisaje de las rutas. Caló hondo una lógica tecno y socioproductiva que profundizó la tendencia al monocultivo con semillas transgénicas o mejoradas junto a la aplicación sistemática y en aumento de insumos de la industria química conocidos como agroquímicos (herbicidas, insecticidas, fungicidas y fertilizantes).

La zona que es objeto de nuestro estudio se encuentra en el departamento de General San Martín, en el centro de la provincia de Córdoba, e integra la región pampeana argentina $y$, por tanto, el área más importante de producción de un reducido número de cultivos extensivos conocidos como commodities agrícolas por ser los más comercializados en el mercado internacional-como son los cultivos de soja, trigo o maíz -.

La franja centro, este y sur de la provincia de Córdoba pertenece a la eco-región pampeana que continua en las provincias de Buenos Aires, sur de Santa Fe, sur de Entre Ríos y este de La Pampa, a lo largo de 55 millones de hectáreas. Caracterizada por su "tierra fértil", permitió sostener el imaginario de una nación potencialmente "granero del mundo". Nuestra zona de análisis está ubicada dentro de esta división por compartir esa cualidad de la tierra y una topografía de llanura.

A pesar que, desde principios del siglo $X X$, dicho Departamento es una de las cuencas lecheras más importantes de la provincia y el país, en las últimas décadas la agricultura predomina en base a la producción de principalmente soja. Estas actividades se combinan, además, con el maní, un cultivo regional de gran importancia económica y cultural que, aunque con altibajos interanuales a causa de la competencia de la soja, sostuvo e incrementó su producción en las últimas décadas gracias al aumento de su rendimiento a través de semillas mejoradas e innovaciones socioproductivas ${ }^{3}$.

En la región pampeana, caracterizada durante el siglo XX por la convivencia de las grandes estancias con numerosas chacras organizadas en torno al trabajo familiar, el cambio agronómico en el uso del suelo también nos relata sobre un proceso de desplazamiento de algunos/as productores/ as que concentró aún más la estructura productiva apalancado en cambios tecnoproductivos, iniciados en las décadas de los años 60 y 70, conocidos como Revolución Verde. Forma parte de un proceso de alcance

3 Aunque no nos detendremos aquí cabe señalar que el dinamismo y la reconfiguración de las economías regionales de la zona ante el avance de la agricultura de commodities es actualmente foco de nuestra investigación en curso. 
global en el cual se introduce no sólo la mecanización de las tareas agrícolas sino, principalmente, semillas mejoradas cuya selección surge de investigaciones en laboratorios que se cultivan en conjunción con plaguicidas sintéticos. Una segunda etapa, conocida como Revolución biotecnológica, introdujo las semillas transgénicas desde la década de los años 90, intensificó la dependencia con los insumos químicos para sostener altos rendimientos e incorporó maquinaria agrícola automatizada y la gestión y control remoto de los cultivos a partir de sistemas informáticos y la microelectrónica -estos últimos conocidos como agricultura de precisión-. El anclaje local de ambas etapas se conjugó con agresivas políticas neoliberales de desregulación y apertura del mercado externo instauradas durante la última dictadura militar de Argentina y profundizadas por los gobiernos de la década de los años 90 que se reflejaron en una estructura de costos que creció significativamente y, a su vez, configuró un creciente endeudamiento de productores en la actividad. Como resultado, se propició la profundización de la concentración productiva en grandes escalas hasta el siglo pasado desconocidas (véase "megaempresas" en Gras \& Sosa, 2013) vía una intensificación del capital en la producción agraria.

A inicios del siglo XXI, este tipo de agricultura se convirtió en los territorios pampeanos en "convencional" -como lo denominan las personas que viven y trabajan en el agropampeano-. Ahora bien, el recorrido que acabamos de realizar no es una mera "contextualización" de nuestra zona de análisis y los procesos socio-políticos de las últimas décadas sino características que lo constituyen como tal. En el próximo apartado, veremos cómo la agroecología se configura relacionalmente con aquella hegemónica lógica de los agronegocios.

Finalmente, cabe señalar que dicha hegemonía de la producción de commodities en Argentina también tendió a invisibilizar y neutralizar la conflictividad. El debate social durante las primeras décadas del siglo XXI estuvo centrado en quién acaparaba la renta agraria -que cristalizó en el año 2008 en la polarización de posiciones respecto al impuesto a las exportaciones de granos, conocido como conflicto por la resolución "125"- y en menor medida en cuestionamientos al modelo tecno y socioproductivo o el reconocimiento de sus consecuencias. En cambio, la conflictividad social fue instalada, desde comienzos de milenio, por quienes fueron o son sistemáticamente afectados/as por la contaminación con agroquímicos rociados en los campos, así como las familias y organizaciones campesinas, indígenas y de producción familiar que sufrieron el despojo de sus tierras y desmontes del bosque nativo ante el avance de la frontera agrícola. En nuestra provincia podemos marcar, al menos, dos grandes hitos, así definidos por su visibilidad internacional, de la oposición de la ciudadanía organizada contra la producción agrícola que utiliza los insumos de la industria biotecnológica.
Por un lado, las denuncias por contaminación con agrotóxicos que consiguió, por primera vez en el país, llegar a una instancia de juicio penal por fumigaciones ilegales y que condenó, en el año 2012, a un productor y a un aeroaplicador, impulsado, desde las periferias de la ciudad de Córdoba, por el grupo de Madres de Barrio Ituzaingó (sobre este proceso de lucha véase Carrizo \& Berger, 2013). Por otro lado, entre los años 2012 y 2016, la resistencia intersectorial a la instalación de la planta de procesamiento de semillas transgénicas de la multinacional Monsanto en la localidad de Malvinas Argentinas, ubicada en el Gran Córdoba; conflicto que concluyó cuando la empresa anunció públicamente que había decidido abandonar el proyecto.

De hecho, fue en relación a dicha conflictividad que empezamos a ensayar las primeras preguntas sobre la agroecología. En lo que sigue, vamos a describir etnográficamente cómo hacen agroecología los y las productores de cuatro establecimientos de pequeña escala que comercializan en el mercado local granos, cereales, hortalizas y productos manufacturados en base a éstos (harinas, conservas dulces y saladas, panificados, entre otros) ${ }^{4}$. Sus protagonistas comenzaron a hacer agroecología -o denominar así a sus prácticas- durante el último lustro y cuentan con diversas trayectorias: tamberos desplazados de la producción, hijos/as de trabajadores rurales que se iniciaron en la producción de soja y decidieron abandonarla por razones éticas y ambientales, jóvenes de la ciudad que migraron al campo "para trabajar la tierra", así como una mujer movilizada por su sensibilidad ecológica y social en un contexto conservador.

\section{A. La herencia chacarera: el peso de la tradición en la agroecología.}

Sobre una de las rutas provinciales del Departamento Gral. San Martín, angosta y con enormes pozos producto del tránsito de maquinaria pesada, se abre un camino de tierra que se dirige al campo de Elvio, más conocido como "Elvito", un hombre de más de 60 años que nació y vivió siempre allí. Al lado de su casa, dos de sus cuatro hijos construyeron sus hogares y viven con sus parejas e hijos. Al fallecer su madre, los hermanos de Elvito y su padre optaron por vender sus partes de la herencia, en pleno auge del crecimiento de los cultivos de soja transgénica impulsado por el ciclo de precios altos de los commodities a principios de este milenio. Él decidió quedarse en el campo, pero pasó a manejar sólo diez de las ochenta hectáreas que lo vieron crecer.

\footnotetext{
4 Como quizás hayan anticipado, la producción certificada como orgánica a través de empresas trasnacionales - por ejemplo, con fines de exportación o para ingresar su producción en las grandes cadenas de retail- no constituye el campo de experiencias analizadas en este trabajo. En contraste, varios estudios indican que incurre en altos costos por lo cual requiere altos rendimientos, tienden al monocultivo y la concentración productiva, al respecto se puede consultar, por ejemplo, Glover y Resnick (2003)
} 


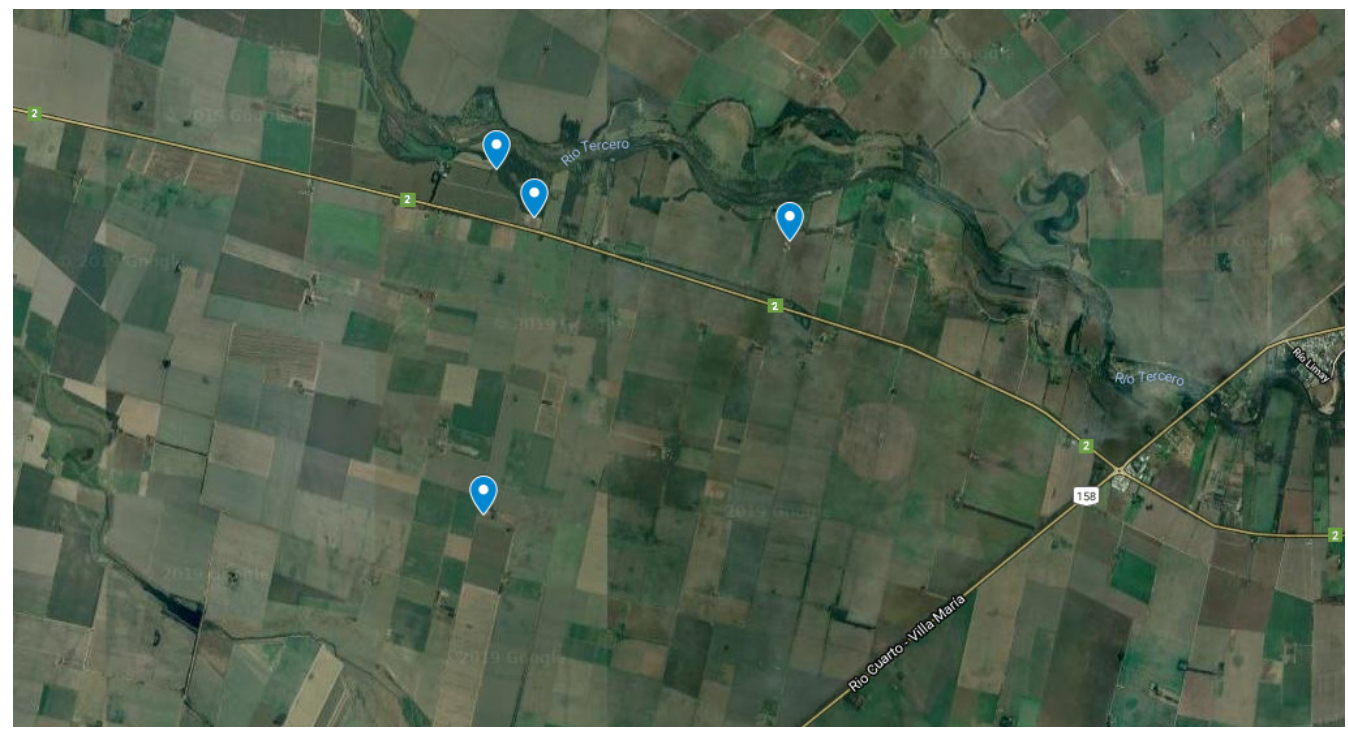

Figura 1: Vista satelital de los campos agroecológicos en la zona rural del Departamento Gral. San Martín. Fuente: Google Earth

Figure 1: Satellite view of the agroecological fields in the rural area of the Department of Gral. San Martín. Source: Google Earth

Rodeando su casa están los cultivos de la empresa local que compró la herencia de sus hermanos y padre. Esta firma nacional es la que más creció, durante este siglo, en el control de la tierra en aquella zona rural vía compra, arrendamiento o contratos de exclusividad con algunos productores. A trescientos metros por detrás de su vivienda está su granja "en el bajo". La denominación refiere a que desde la ruta provincial el terreno tiene pendientes escalonadas en dirección al río Ctalamochita. En la última franja se ubica la granja de Elvito, una zona que tiende a inundarse. De ahí que su vivienda esté ubicada en la zona más alta, a pesar de encontrarse rodeada de la zona productiva de aquella empresa. Desde la ruta hasta la casa de Elvito sólo se ve alrededor llanura y campos sembrados de verdes radiantes o con rastrojos de un amarillo pálido, según la época del año. Es la agricultura que denominan mis interlocutores de la zona como "convencional", que tiene la capacidad de generar una apariencia de homogeneidad productiva en la zona. En su granja, en cambio, tiene más presencia el monte que lo rodea formando paredes que cierran la visual y protegen de los vientos, el suelo está húmedo y por zonas barroso.

A Elvito lo llaman "chacarero" sus vecinos y vecinas. Esta noción propia del espacio social rural argentino configura lo que la sociología llama un farmer pampeano (Archetti \& Stölen, 1975). Como clase social, su origen remite a la constitución de la agricultura familiar capitalizada, ligada a las luchas por el acceso a la tierra de chacareros y colonos que trabajaban para las grandes estancias arrendando o con otras formas de contratación-.

Más allá de los debates al interior de las ciencias sociales para mis interlocutores tiene su propia especificidad definir a Elvito como "chacarero". O más aún "chacarero chacarero", donde la redundancia aporta una afirmación de una estricta correspondencia ante los cambios recientes en el ámbito rural que hacen que algunos productores ya no sean considerados como tales. Esta noción les habla de una trayectoria familiar rural, un manejo de superficies que se cultiva con movimientos de suelo y haciendas que "se largan al campo" para que se alimenten. Es decir, una forma de producir que denominan "tradicional" que distinguen de la convencional como también de un "gusto" por un modo de vida rural.

Como chacarero de esta zona -cuenca lechera-, la actividad principal de Elvito fue el tambo hasta que perdió el control sobre lo que eran las tierras familiares. En la actualidad, Elvito organiza sus jornadas diarias en un marco de lo que la literatura de estudios rurales y campesinado caracteriza como "pluriactividad". Tiene animales y aunque no prima la cantidad, sí la diversidad. Durante el periodo que duró mi trabajo de campo -2017 y 2019- mantuvo en promedio una hacienda de cuatro chanchas para cría de chanchos, de cincuenta cabezas de ovejas y un par de vacas con sus terneros. Los alimenta con las pasturas que siembra de avena, cebada y alfalfa. La otra actividad que lleva adelante es la reproducción y cría de aves que es usual ver sueltas alrededor de su casa, destacándose la diversidad de colores.

La agricultura la desarrolla en tres lotes contiguos que tienen alrededor de dos hectáreas cada uno. En dos de ellos siembra las pasturas para los animales y en el tercero, durante el ciclo de primavera-verano, cucurbitáceas: sandías, melones y zapallos. Cultiva para cosechar sólo estas plantas que no necesitan tantos cuidados porque cuenta con pocas herramientas para mecanizar el trabajo y la ocasional ayuda de alguno de sus hijos o de integrantes de los otros campos agroecológicos.

Según me supo contar un día, en el momento en que su familia decidió vender el campo, su experiencia en el manejo tradicional le decía que: "ochenta hectáreas era para vivir una familia". Lo anterior nos permite entender por qué Elvito cuando pasó a tener sólo diez 
hectáreas se encontró "medio con miedo". Quedarse en el campo no era una decisión fácil porque entendía que su porción de tierra heredada no era suficiente para sustentar los ingresos necesarios de una familia con hijos adolescentes.

En aquella época, Elvito veía cómo los chacareros de la zona dejaban el campo, sea vendiendo, arrendándolo o incorporándose como contratistas: "Porque para la soja o el maíz no hace falta estar viviendo en el campo" -me supo explicar-. En sintonía, los datos -aún provisoriosdel último Censo Nacional Agropecuario del año 2018 arrojaron una disminución del $20 \%$ de los establecimientos agropecuarios de la provincia de Córdoba y una caída del $35 \%$ en la cantidad de trabajadores rurales empleados respecto al 2002. Esta tendencia es una continuidad de la ya registrada en los Censos anteriores, con una dirección equivalente en el territorio nacional, siendo los establecimientos pequeños y medianos los que más vienen disminuyendo.

Mientras la mayoría desistía, Elvito fue uno de los que decidió quedarse en el campo porque a él le gusta vivir y trabajar allí. Cuando sus hermanos y padre vendieron sus partes del campo, Elvito llegó a un acuerdo con uno de los propietarios de la empresa local para quedarse con la vivienda familiar y las diez hectáreas en el fondo del campo donde armó su granja. Este hombre, un importante empresario, aunque nacido y crecido en otro pequeño pueblo de la zona, de algún modo, pudo comprender el planteo de Elvito que afirmaba que no podía irse del campo.

Elvito continuó trabajando con sus ovejas y terneros que pastan libres, sus gallinas que picotean el suelo alrededor de su vivienda, los chanchos que carnea con sus hijos y nietos y los melones, sandías y zapallos que ofrece en el cruce de rutas y ferias agroecológicas. Su manejo de la producción tradicional lo dejó sin incursionar en las últimas innovaciones de la biotecnología porque "en los tambos los químicos no existían. Existían nada más para los que hacían cosecha". Aunque vive rodeado de la agricultura convencional y, por tanto, sus agroquímicos, él no los adiciona a su producción. No obstante, hace sólo pocos años escuchó por primera vez la palabra agroecología, cuando entró en contacto con los establecimientos que se instalaron a pocos kilómetros de distancia de su casa.

Actualmente Elvito sabe que su manejo tradicional es agroecológico para los campos vecinos con los que articula y sus consumidores. No le preocupa demasiado ahondar en conceptualizaciones, continuó produciendo "como se hacía antes".

\section{B. Regenerar un vergel donde antes sólo había desmonte}

A pocos kilómetros de la granja de Elvito se encuentra "Los pioneros", un establecimiento llevado adelante por Alicia, una vital mujer de 68 años, que denominó así a su campo por su abuelo y el de su ex marido, migrantes europeos que "con esfuerzo y desde abajo" crearon las condiciones para la reproducción de sus familias. Para las personas de esta zona de la pampa cordobesa Alicia es "una pionera" que le dio a la palabra agroecología un referente concreto con su campo, que inicio en el año 2002.

En la década de los años 70, Alicia descubrió su gusto por la vida rural al casarse con un hombre de la zona, José María, integrante de una familia de tradición agropecuaria y una de las que más tierras manejaban en la zona. José María fue parte de la primera generación con estudios universitarios de su familia y cuando él se recibió de ingeniero agrónomo, ambos se fueron a vivir al casco de la Estancia familiar que estaba deshabitado. Alicia, por

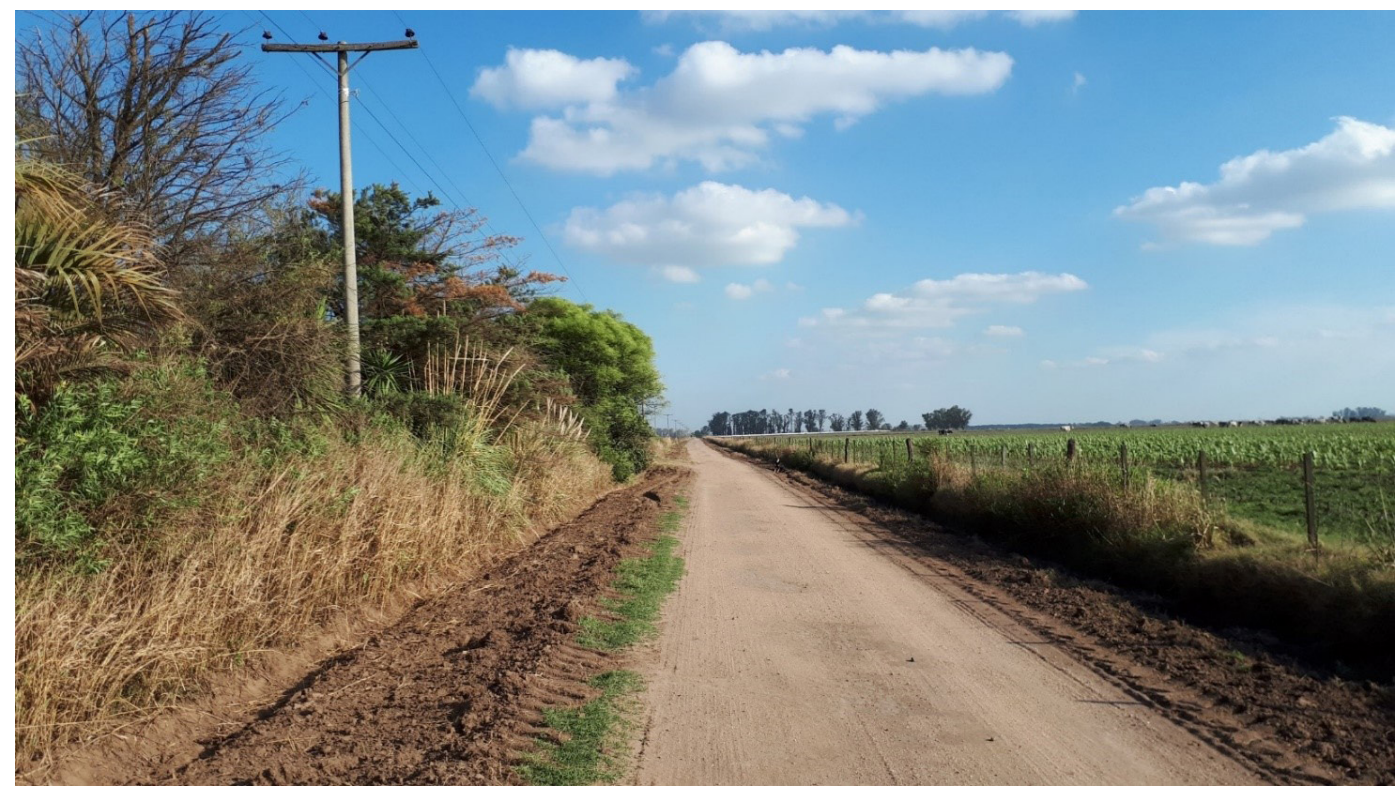

Figura 2: A la izquierda se observa el ingreso al campo "Los Pioneros"; a la derecha se observa un cultivo convencional. Archivo propio.

Figure 2: On the left you can see the field "Los Pioneros"; on the right a conventional crop. Own archive. 
entonces con 25 años, aunque había crecido en la ciudad de Córdoba, en aquellos primeros años de su matrimonio descubrió su afinidad con un modo de vida rural. Durante la crianza de sus cuatro hijos, no dejó de incursionar en la horticultura para autoconsumo y la apicultura, mientras su marido se ocupaba del tambo y la agricultura.

Por su ímpetu innovador, José María fue de los primeros en incursionar en la producción de soja en la zona. No obstante, al igual que para muchos productores agropecuarios, desde finales de los años 80 y durante la década del 90, la inversión productiva a través del crédito se convirtió en una deuda impagable (Manildo, 2013) y José María perdió la mayor parte de las tierras que manejaba y se retiró. Mediando el año 2000, Alicia y José María se separaron y ella inició un proceso de rearmar su proyecto de vida. Por entonces, estaba próxima a cobrar una herencia de su familia y sabía que era con lo que contaba para poder acceder a un lugar donde vivir y un vehículo para su movilidad. Con ese dinero compró 5 hectáreas que convirtió en Los Pioneros.

Como en sus primeros años de matrimonio, aunque 25 años después, su nuevo hogar contaba con cocina y ducha a leña y no estaba conectado a la red eléctrica por lo que Alicia optó por instalar paneles solares. A su campo lo rodean otros destinados a la agricultura convencional por eso lo primero que hizo fue empezar a plantar y germinar árboles, con un primer cometido de crear un cordón forestal para protegerse de los fuertes vientos que caracterizan a la zona y en consecuencia la deriva de las fumigaciones linderas.

Estaba decidida a probar otros métodos. Siguiendo las enseñanzas del agricultor y filósofo japonés Masanobu Fukuoka, Alicia diseñó su campo por zonas: una de monte leñero, de monte autóctono, otra de frutales, otra hortícola, un estanque, así como algunos espacios para la contemplación de la naturaleza. Y aunque el estado de desarrollo de las especies plantadas es muy disperso, en conjunto le dan una gran diversidad y frondosidad al establecimiento. Esta visión plantea, al igual que la agricultura biodinámica, concebir al campo como un organismo que logra autorregularse. No obstante, en un terreno que estaba sin más que unos árboles aislados y pastizales, para Alicia fue necesario primero recrear las condiciones propicias a través de la siembra y transplante de especies. Dar a la tierra lo que necesita para regenerarse.

Esa "ayuda" -como suele calificar Alicia- al ecosistema es el rol que se predispone a ocupar. Por ejemplo, en abril de 2018, tras una inusual sequía en verano de 90 días, en los campos que nos rodeaban, donde desarrollan agricultura convencional, se veían rastros de maizales secos que sólo llegaron a crecer veinte centímetros o plantas de soja quemadas. Si bien no podríamos decir que Los Pioneros no se vio afectado por la sequía de verano, si podemos dar cuenta de su rápida recomposición al comenzar las lluvias en marzo.

Empero, su campo nunca fue "productivo" en los términos en que miden los rendimientos las Ciencias Agrarias. Alicia siembra plantas de hortalizas, frutales y aromáticas a las que les cuesta sobrevivir porque están expuestas a fuertes vientos o porque les llega la deriva de las fumigaciones. Tanto es el impacto de los químicos que una vez, cansada de plantar y cuidar árboles para el cordón forestal y protección de su campo, decidió labrar un acta con una escribana para dejar asentado que, al ser alcanzados por la deriva de los agroquímicos rociados en los campos linderos, sus plantas no resistían y morían.

Figura 3: Recorrido por músicos en una de las huertas de Pueblo Mampa. Archivo propio.

Figure 3: Tour by musicians in one of a vegetable garden in Pueblo Mampa. Own archive.

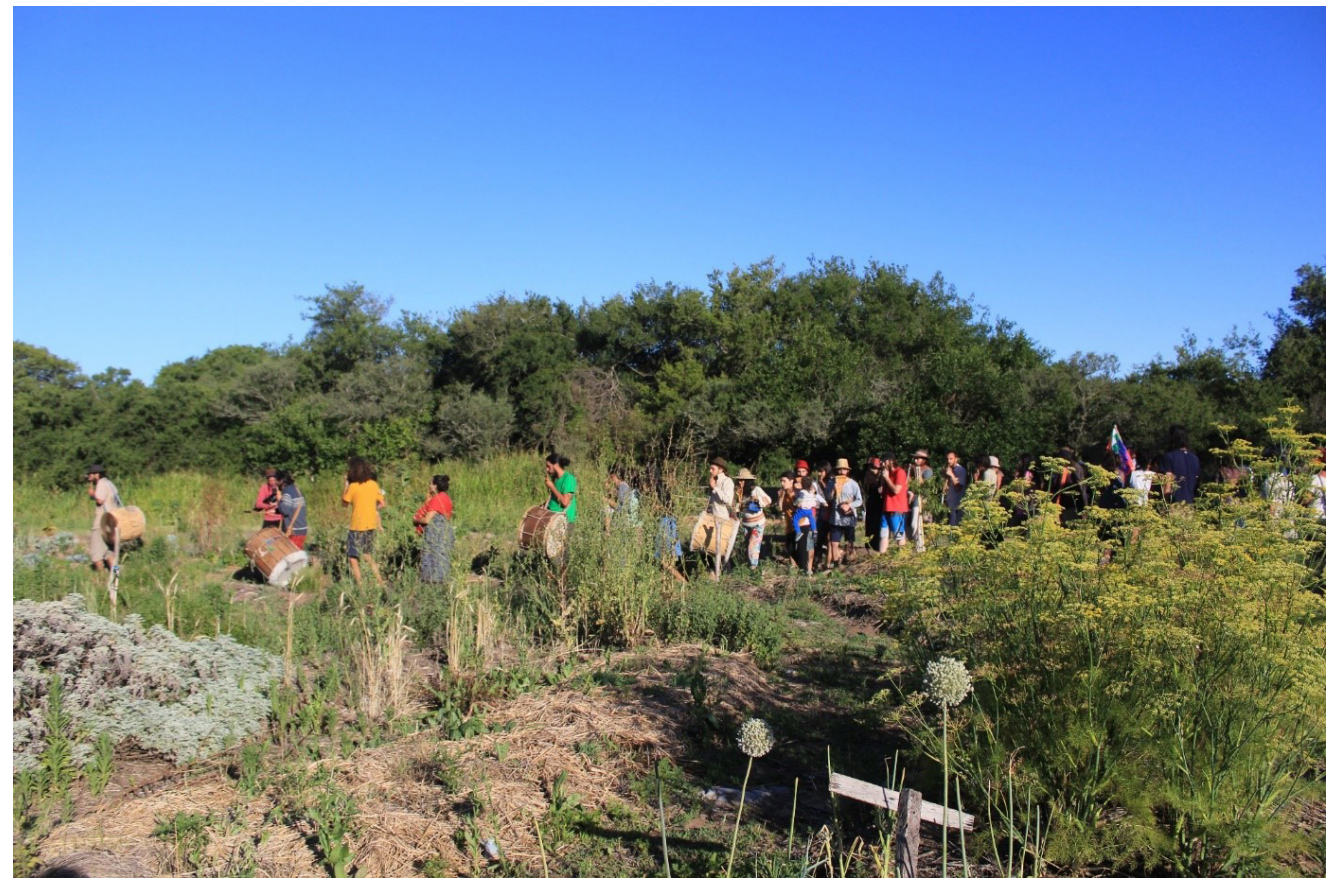

ISSN 1852-060X (impreso) / ISSN 1852-4826 (electrónico) 
Es palpable la angustia y frustración que le produce ver a sus plantas enfermar y morir, no obstante, aunque añora una reconversión productiva en el agro, más de una vez la escuche sostener una mirada comprensiva con sus vecinos y familiares que hacen agricultura convencional y fumigan. Recuerdo que una tarde, después de un rato de quejas por las complicaciones que le traía la fumigación de los campos linderos, me miró y me dijo: "Igual, los entiendo. Si sos productor y tenés 100 hectáreas sos un miserable en este sistema".

A lo largo de estos más de quince años, Alicia se enfocó en reforestar y regenerar los suelos. Al vivir de su jubilación no precisa asegurar cosechas para vender y su foco está en regenerar su campo como ecosistema y abastecer su autoconsumo. Alicia es pionera en una lógica centrada en el dar para regenerar los ecosistemas en la zona.

\section{Producir vida comunitaria y rural para producir alimentos}

Para caracterizar al establecimiento Pueblo Mampa, una aldea permacultural conformada por jóvenes, quisiera comenzar recordando una mañana de diciembre del año 2016 en la que se preparaban para cosechar. Aquel día el trigo se mostraba de un dorado intenso y prometía un rendimiento similar al del año anterior (2015), mejor que el de otros campos de la zona que utilizan insumos químicos. Pero este trigo no había crecido al amparo de dichos productos que son rociados sobre la vegetación que crece de manera espontánea o los insectos que intentan alimentarse de él. Creció sin ningún aditivo sintético, acompañado por otras plantas que se desarrollaban a su alrededor y la mirada atenta de jóvenes de trayectoria urbana que se fueron a vivir al campo para "guardanear" el monte nativo y los alimentos que producen en estas tierras -tomando la expresión nativa que convierte el sustantivo guardián en verbo-.

Estaba nublado el cielo cuando la vieja cosechadora ingresó al campo para iniciar las labores. Avanzaba lenta entre el aire cargado de humedad. Era un aviso de que la tormenta estaba en camino y eso no era bueno. La cosechadora comenzó a trabajar y a los minutos se abrió paso una tormenta de granizo que cayó al suelo como piedras arrojadas desde las nubes. El cielo se cerró. Después siguió la lluvia y el trigo quedó allí tendido. No se pudo cosechar y con el pasar de los días se descompuso sobre la tierra.

Nano, uno de los huerteros de este proyecto era quien me relataba la historia del día que no pudieron cosechar el trigo: "No lo podíamos creer, quien manejaba la cosechadora no apagó el motor porque no aguantó escuchar el impacto de la piedra cuando caía", recordaba. Por mi parte, era la tercera vez que yo escuchaba la anécdota y me seguía anudando de angustia la garganta imaginar cómo había sido ese día. El trigo estaba listo para cosecharse, pero la tormenta llegó antes. Alli quedaron los 130 kilos de semillas de trigo cultivadas en 6 hectáreas durante cinco meses. "Perdieron todo" registré en mi anotador.

Progresivamente entendí, al volver sobre mis registros y conectarlos con lo que sucedía en la aldea permacultural, que sus habitantes no vivían como si hubieran "perdido todo". Incluso nunca se expresaron en esos términos. Más bien afirmaban que "quedó para la pacha", "ahora es abono verde", "es un aporte de nutrientes a una tierra muy dañada". Con esto último referían a que en aquellas tierras se realizó durante años agricultura convencional con grandes dosis de químicos y de extracción de nutrientes.

En cambio, cada día se dedicaban a las tareas hortícolas, a la construcción de sus viviendas, a la producción de alimentos que califican como "sanos" y "medicinales" y comercializan de manera directa a consumidores "de la ciudad". Ahora bien, que no lo vivieran en términos absolutos como pérdida, no quita que en términos relativos sí lo fuera. El trigo que no fue recibido por los y las agricultores lo tomó otra entidad, la tierra. Y les demandó reacomodar sus actividades productivas porque la comercialización de éste era una de sus principales fuentes de ingresos, acumularon deudas con proveedores y familiares, así como tuvieron que organizar actividades especiales para recaudar dinero como, por ejemplo, cenas en el campo.

Aquel trigo que no lograron cosechar nos permite comenzar a asir una lógica que ponen en movimiento para hacer agroecología en Pueblo Mampa, que articula un principio de dar a la tierra para regenerar los ecosistemas en aquellas tierras durante años destinadas a cultivos convencionales.

Esta lógica manifiesta en sus valoraciones, decisiones y acciones propongo, tomando prestada una expresión del antropólogo Bronislaw Malinowski (1985), se puede comprender organizado entorno a "fuerzas vinculantes" entre humanos y los no-humanos de "cadenas de servicios mutuos, un dar y tomar que se extiende sobre largos periodos de tiempo". Hacer agroecología en Pueblo Mampa implica dar y esperar a recibir a lo largo del tiempo. Propongo que aquel principio de dar para regenerar los ecosistemas - que ya nos había presentado Alicia- implica para nuestros interlocutores de la Aldea permacultural una reparación en la vinculación inter-especies e inter-generacional que el egoísmo y arrogancia humana quebrantó. Entiendo que es un principio en tanto opera como un ordenador o estructurador de las decisiones, valoraciones y acciones, que les insta a no reprochar ante una sequía, granizo o insectos que se comen los cultivos.

Aquel principio en Pueblo Mampa es compensado a 
partir de encontrar lo que sus integrantes denominan la "abundancia disponible". Me refiero al ejercicio de una gramática creativa que se construye a partir del habitar los ambientes de la vida (Ingold, 2015) que les permite descubrir e identificar alimentos no convencionales (frutos de árboles como es la algarroba, hojas, hongos y flores comestibles no convencionales, etc.) así como reciclar, reutilizar y recuperar materiales para producir energía, la construcción de sus viviendas, herramientas, ropa o recibir las más diversas donaciones.

Pueblo Mampa, a pocos kilómetros de Elvito y Alicia, es protagonizado por jóvenes que hacen justicia a la categoría neorural (Nogué, 1988) acuñada por las ciencias sociales para referir a los procesos migratorios protagonizados por personas con trayectorias urbanas y de clase media (véase también Quirós, 2014), en general, sensibilizados por los discursos ecologistas y movimientos contraculturales. De hecho, trabajan y construyen sus viviendas de adobe en 50 hectáreas, donde 18 son productivas y el resto es monte nativo en protección, que les fueron cedidas en comodato por una Orden religiosa católica, dado el perfil social y ecológico del proyecto. En la actualidad, la aldea está habitada por tres familias con hijos e hijas (en total cuatro niños y niñas), una pareja y tres jóvenes, que hacen un total diez personas adultas de entre 25 a 37 años. A su vez, voluntarios y voluntarias que viajan de distintos lugares del país y, a veces, del extranjero adicionan a la vida de la aldea entre seis y diez personas en promedio durante algunos momentos del año.

Para quienes integran Pueblo Mampa construir, vivir y trabajar en una aldea ecológica que definen de "sistemas cerrados" apunta a evitar el "derroche" de materiales y energía que entienden es propio de la vida urbana. Por ejemplo, construyen sus viviendas con materiales disponibles en el monte como barro, estiércol y troncos; con descartes de la ciudad como son viejas ventanas y puertas. De ahí que el gasto monetario de dos de las casas que construyeron durante mi trabajo de campo haya sido de aproximadamente 15 US e implicado alrededor de tres semanas de trabajo por unidad habitacional. Estas experiencias les permiten a quienes integran Pueblo Mampa re-afirmar que "no existe escasez" y que hay que aprovechar la "abundancia disponible" en la naturaleza o los descartes de la ciudad y, de este modo, entendemos tensionan pragmáticamente el paradigma del desarrollo industrial y sus a priori principales.

Principalmente se presenta en Pueblo Mampa que sus integrantes entienden su quehacer cotidiano como un "servicio", un término que recorre las más variadas manifestaciones espirituales y que da cuenta de una práctica de entrega o donación. No obstante, estas renuncias, que configuran un tipo de experiencia de despojo, no están libres de angustias y contradicciones propias de lo que va a contrapelo de nuestra socialización capitalista y occidentalizada- que se pueden manifestar en "extrañar comer una golosina", "ver una serie", ir a la ciudad a "ver un poco de gente" o que, también, explica la constante rotación en el grupo estable de integrantes en Pueblo Mampa. De ahí que una de las cuestiones que llamó mi atención cuando llegué a la aldea por primera vez fue encontrarme con personas que, antes que hablar sobre técnicas de agricultura, me contaban de los cambios que estaban viviendo a nivel subjetivo, de lo que "soltaban" de su vida anterior y la importancia de "despertar la conciencia".

Propongo que si la aldea permacultural, sin luz eléctrica, con energía a fuego, con provisión de agua con un molino de viento, con casas construidas de barro, rodeada de hermosas huertas diseñadas para que puedan ser recorridas y contempladas, podría ser caracterizado como una economía de carencia desde los parámetros convencionales, para quienes allí habitan -parafraseando



Figura 4: Mabel y Mauricio (adentro de la maquinaria) preparándose para una jornada de cosecha. Archivo propio.

Figure 4: Mabel and Mauricio (inside the machinery) preparing for a harvest day. Own archive. 
a P. Clastres- constituye un "rechazo a un exceso inútil" (Clastres, 2008, p. 166).

\section{Diseñar la agroecología entre la herencia chacarera} y las ciencias agrarias.

"El otro día encontré una lombriz", con un entusiasmo que desbordaba alegría, me contó Mabel, ingeniera agrónoma y productora, mientras transcurría el tercer ciclo de producción agroecológica en Sol y Luna. Hacía medio año que yo había iniciado mis visitas a los campos de la zona y había aprendido que para mis interlocutores la tierra que se cultiva muestra su "buen estado" cuando tiene "mucha vida". Es decir, cuando está habitada en la superficie y adentro, no sólo con pasturas y plantas sino, también, por muchos microorganismos, insectos, hongos y cualquier otra especie. Por ello, podía entender la alegría de Mabel, pero me faltaba algo más para ponderar el anuncio. Aquella lombriz fue la primera que encontró en las tierras que cultivan.

Mabel junto a su pareja Mauricio son dos jóvenes profesionales del agro que se iniciaron en la agroecología en el año 2015, tras dejar atrás experiencias laborales en la producción convencional, haciendo principalmente soja transgénica. Sol y Luna nació como un proyecto para experimentar otra forma de producción agropecuaria que, sin estar planificado, les conectó con los saberes chacareros entre los que crecieron en su niñez y adolescencia con sus familias siempre dedicadas a la actividad rural. Actualmente alquilan quince hectáreas donde producen granos sin gluten (trigo sarraceno, lentejas, arvejas, mijo, maíz, entre otros) y en esas pocas hectáreas pudieron experimentar con más diversidad de cultivos que en sus más de diez años en "la convencional".

Cuando empezaron a producir agroecológicamente decidieron diseñar sus cultivos de forma tal de propiciar la convivencia entre distintas especies. Por eso, desde 2017 decidieron subdividir los lotes de agricultura en parcelas de una hectárea y dejar un espacio que las rodee delimitado para que sean "corredores biológicos". Este consiste en un área lindera a cada lado de la parcela cultivada de un tamaño de dos metros de ancho y noventa de largo ${ }^{5}$. Es decir, siembran una hectárea y alrededor dejan un espacio que no se cultiva y su fin es que se desarrolle y asiente vegetación espontánea e insectos (aquellos que en la agricultura convencional son considerados "plagas" que deben eliminarse). Allí empezaron a plantar árboles y especies con flores y nectarios, las cuales no forman parte de la siembra y quedan ahí para fomentar el "autocontrol entre las especies". Es decir, encontramos en las prácticas que llevan adelante Mabel y Mauricio una acción deliberada que contempla un lugar para que

5 La relación del cordón biológico con la parcela surge de cálculos a partir del conocimiento de las ciencias biológicas que define que los insectos caminadores se mueven veinticinco metros y los voladores cincuenta. puedan habitar otras especies.

El énfasis de nuestros interlocutores en la creación de condiciones -y necesidad- para que la tierra vuelva a estar habitada por la mayor y más variada cantidad de especies y entidades (con la no utilización de químicos, con el diseño de una agricultura de diversidad de cultivos, con la creación de corredores biológicos), contempla que la interdependencia entre especies es condición necesaria para la producción de alimentos.

El trabajo de la antropóloga estadounidense Anne Tsing (2015, p. 182) nos permite comprender otras dimensiones de aquella primera lombriz en las tierras que cultivan. A partir del hecho de que algunos hongos son compañeros vitalicios de algunos árboles, recupera el concepto de "simbiosis", que refiere a la "convivencia interespecies mutuamente benéfica". Tsing nos propone que la simbiosis es un fenómeno más habitual de lo que creemos, que hace al compañerismo entre especies.

La perspectiva de quienes llevan adelante Sol y Luna, atravesada por sus trayectorias en familias chacareras y su profesionalización en las Ciencias Agropecuarias, nos permite recuperar otra dimensión de la agro-eco-lógica. Aquellas cadenas de dar y tomar a lo largo del tiempo se pueden entender mejor en los términos de la filósofa y bióloga Donna Haraway (2016, p. 101) como hacer florecer ricos "arreglos" o "ensambles" multiespecies (multispecies assemblages) en tanto acciones deliberadas que contemplan a las especies y entidades que habitan el mundo rural como activos interactuantes de un sistema de vida. Con sus decisiones y prácticas exploran alternativas para obtener sus alimentos, a la par de poder cohabitar el mundo con otras especies.

Por otro lado, esta experiencia hecha luz sobre una dimensión que las otras anticiparon: los procesos imbricados que constituyen el hacer agroecología en la región pampeana. Por ejemplo, porque necesitaban el ingreso monetario por un año más Mauricio continuó trabajando en la empresa de commodities, la misma en la que Mabel dirigió durante 10 años cultivos de soja. "Dejar de hacer soja" fue un cambio que operaron en complejas transiciones socioproductivas.

\section{Notas sobre la agroecología pampeana}

Intentamos en estas páginas explorar la productividad de la pregunta antropológica sobre el cómo del hacer agroecología en algunos establecimientos del agropampeano cordobés. Esta forma de indagar habilitó un desplazamiento desde la pregunta por el tipo de actividades que se realizaban hacia el cómo se realizaban, para recuperar las agro-eco-lógicas que organizan y estructuran las prácticas de producción. En otras palabras, realizar este desplazamiento analítico, más adelante, puso en relieve que el foco de esta investigación 
no estaba en confirmar si en aquellos campos hacían o no agroecología, o eran o no experiencias disruptivas, sino más bien en comprender cómo hacían lo que hacían, es decir, en relación con quiénes, atentos a qué problemas, buscando qué resultados. Por otro lado, levantar la pregunta por el cómo implica entrar de lleno a un tópico relevante en este universo social. Es decir, el cómo hacer agricultura (o cómo no hacerla) nos llevó a indagar el núcleo de la controversia social que atraviesa la producción agropampeana.

Pudimos identificar aquí que Elvito, así como Alicia y su exmarido, incluso con sus distintas posiciones de clase, coexistían en el mundo chacarero. Para continuar habitando las tierras pampeanas debieron, al igual que las economías regionales, reconfigurar sus actividades y con ello sus vidas. Mientras que para la mayoría de los chacareros la disyuntiva se planteaba entre incorporarse en la agricultura convencional o "dejar todo e ir a la ciudad", Elvito y Alicia, no sin miedos y frustraciones, decidieron quedarse por su gusto por la vida rural. A Elvito y Alicia producir de un modo tradicional y regenerar un campo orgánico les permitió existir en la hegemonía de la agricultura convencional. Para los y las voluntarias que pasan por Pueblo Mampa, así como para la mayoría de sus integrantes, viajar como mochileros o con un destino "abierto" fue la forma para salir del modo de vida que buscaban cambiar, la agroecología los y las encontró "en el camino". Mabel y Mauricio, oriundos de localidades de tradición agropecuaria, más que viajar para "descubrir" nuevos lugares, volvieron a un territorio "familiar", aunque extraño tras sus experiencias recientes.

Cuando inicié mi trabajo de campo llegué primero a Pueblo Mampa porque un estudioso y militante de la soberanía alimentaria me aseguró: "tenés que conocerlo". Este establecimiento parecía ser un excelente "modelo" de agroecología y podría haber agotado allí mi exploración. No obstante, la perspectiva relacional y procesual de la antropología de la política me invitaba a seguir los hilos de sus relaciones y eso me puso en contacto con las otras experiencias de la zona, todas cercanas entre sí, heterogéneas y en convivencia. Los pequeños campos ecológicos del Dpto. Gral. San Martín rodeados principalmente de soja transgénica nos llevaron a entender que no podíamos comprender la agroecología aislada. Más aún, la experiencia etnográfica nos permitió comprender que no sólo los establecimientos vecinos hacían soja, sino también algunos de nuestros interlocutores de la agroecología habían incursionado previamente. También hacían soja algunos productores que les prestan tierras o maquinarias, así como sus vecinos, familiares o ex compañeros/as de estudios o trabajo. Al indagar las tramas de relaciones que componen la producción agroecológica nos abrimos a la complejidad del entramado social que nos permitió comprender que en el hacer agroecología de las personas se presentaban no sólo relaciones de oposición con el agronegocio, sino también relaciones de vecindad, negociación, tolerancia, indiferencia, dependencia, entre otras; y, además, habilitó a incorporar en aquella trama de vinculaciones la diversidad de actores y agencias que habitan el mundo rural.

Lo anterior me da pie, además, a reconocer que este trabajo está en gran medida en deuda con la perspectiva del antropólogo inglés Tim Ingold que nos permitió comprender que debíamos extender la trama de relaciones que estábamos etnografiando cuando entendimos que habitamos, más que un mundo de "objetos", un mundo de "cosas" que están "vivas" (2015, p. 42). Un año después de iniciado mi trabajo de campo, al volver sobre mis registros comprendí que las relaciones multiespecies en los campos agroecológicos eran vividas como relaciones reales (y hasta cruciales) entre distintas entidades inmanentes al mundo. Incluso existen situaciones en las cuales los vínculos con plantas, fenómenos climáticos y otras especies dejan entrever la centralidad de estas relaciones en sus vidas. Esto nos permitió reconocer que aquello que a primera vista puede ser lisa y llanamente considerado como un cambio tecnológico u organizacional, además, constituye sus mundos para las personas que allí viven y trabajan.

La agro-eco-lógica que operan nuestros/as interlocutores supone un vínculo entre especies que reconoce la interrelacionalidad y la agencia inmanente de cada uno/a en esa relación, que les permite -en principio- coproducir alimentos. En definitiva, no aplicar venenos cuando plantas, insectos, hongos se presentan en los cultivos, apunta a respetar la autonomía de las otras especies y confiar en la malla que se teje entre las entidades vivas, incluso cuando hay "pérdidas" (como el caso del trigo que repusimos, entre muchos otros).

Al examinar formas de producir alimentos para autoconsumo y comercializar en la zona, a la luz del contexto social y de la vida de las personas, las pusimos en el centro del análisis como proceso. En lugar de los movimientos campesinos o por la soberanía alimentaria, como un todo anónimo, nos encontramos con personas con sus propias trayectorias y situadas en un tiempo y espacio, con sus deseos, pero también con sus miedos y frustraciones y-principalmente- en relación con muchos otros, sean tanto humanos como no humanos.

Esta mirada relacional que nos enseñó la antropología de la política nos permitió abrirnos camino a una comprensión de la agricultura ecológica en el mundo social del cual forma parte. La región pampeana es un universo de chacareros, trabajadores rurales, los de "poca superficie", las "grandes", "a los que les fue bien con la soja", "los que se fueron", "contratistas", "la agronomía local", "las acopiadoras", "la industria" y como recorrimos aquí, quienes se quedaron, se reconvirtieron y aquellos 
que llegaron para empezar "a trabajar la tierra".

A través de las experiencias de Elvito y Alicia anticipamos, aunque no ahondamos, en las formas de producir ancladas en las relaciones con animales, plantas, insectos, el clima, entre otras. La agroecología de Elvito implica trabajar el campo "como se hacía antes", echando mano del patrimonio cultural chacarero: mueve la tierra y cultiva cucurbitáceas y pasturas; reproduce y cría animales; cosecha y carnea para vender. Recupera un pasado cercano, del cual fue protagonista junto a su padre, tío y abuelo. Como buen (ex)tambero, sabe que "en el campo hay que estar día y noche, con frío y calor". Por su parte, la agroecología de Alicia opera en un principio ecológico de dar a "la Pachamama", a los ecosistemas, sin perseguir una cosecha ni inmediata ni detenidamente calculada. Mientras que la tradición le indica a Elvito que para cosechar también tiene que dar, debe nutrir la tierra y moverla, se orienta a propiciar las condiciones para recibir. En cambio, las acciones de Alicia se dirigen a entregar, su vida gira en torno al proyecto que inauguró con su campo.

En Pueblo Mampa hacer agroecología requiere vivir juntos/ as en el campo en una organización socioeconómica donde las esferas de la producción y reproducción se reinsertan en un ámbito de resolución colectivo. Esto les entrama en una interdependencia densa entre los y las integrantes del proyecto y, a su vez, con el ecosistema. Como "guardianes del monte" orientan sus acciones a la generación de condiciones para la reparación ecológica -parcial y compuesta- de los ecosistemas.

Por otro lado, los jóvenes profesionales del agro que conforman Sol y Luna nos permitieron hacer inteligible los procesos imbricados que constituyen el hacer agroecología a través de sus pasos por la agricultura convencional, sus tránsitos por la formación universitaria y sus trayectorias familiares chacareras. La agro-eco-lógica que ponen en juego opera un principio de dar que articula sus conocimientos locales producidos en esa variedad de experiencias vitales junto a cálculos para que todos/as puedan recibir, humanos y no humanos.

Así pudimos vislumbrar que la agroecología opera como un paraguas que alberga y conecta variadas trayectorias y búsquedas que comparten y descubren el gusto por la vida rural. Finalmente, no voy a eludir la pregunta sobre qué significa, entonces, hacer agroecología en los campos del Dpto. Gral. San Martín. El análisis etnográfico nos permitió entender que no se reduce tan sólo a técnicas o productos. Incluso con las diferencias que comportan entre sí las experiencias analizadas, hacer agroecología es, principalmente, tejer vínculos. Aquellos vínculos que garanticen recrear las cadenas dar y recibir a lo largo del tiempo y que permitan que cada quién encuentre su lugar en el ecosistema, personas humanas incluidas. Dichas tramas de relaciones son condición de posibilidad para que puedan resistir y existir, para crear formas de vivir y trabajar en los márgenes de la hegemonía del agronegocio.

\section{Reflexiones finales}

Este trabajo plasma situadamente que la agroecología constituye uno de los caminos posibles del mundo rural que, además, se bifurca en variadas formas de producir alimentos sanos y de ponderar el gusto por la vida rural.

La experiencia etnográfica nos permitió desplazarnos de indagar la agroecología, en singular y como un marco normativo, hacia las prácticas agroecológicas, en plural y ancladas en el hacer cotidiano de las personas. En ese sentido, entendemos que este trabajo busca contribuir a la comprensión de cómo se entraman en los territorios formas de vivir y trabajar que el predominio del cultivo de soja en la inmensidad de las llanuras tiende a invisibilizar.

Reparar en ese desplazamiento que enfatiza, más que en una identidad sustantiva, en una capacidad de agencia nos permitió volverlo productivo en el análisis. A lo largo de este trabajo, intentamos mostrar cómo, aunque constreñidas/os por condiciones estructurales que tendían a expulsarles de la vida y trabajo rural o a presentarles como "única opción" hacer commodities, quienes hacen agroecología despliegan estrategias que les permiten existir en el mundo agropampeano cordobés. Al preguntarnos cómo lo hacen pudimos recuperar la dinámica que crea la posibilidad de producir y reproducir existencias al margen de la agricultura convencional, en relación con muchos otros humanos y no humanos. En otras palabras, seguir sus acciones y decisiones nos permitió reconstruir una eco-lógica en la producción de alimentos, de dar y recibir, que entrama a quienes habitan las tierras pampeanas.

Además, frente a una literatura sobre la temática que se centra o bien en las dimensiones agronómicas (manejo de cultivo, rendimientos, entre otras) o bien en el antagonismo estructural entre dos modelos agrarios -uno propiamente capitalista y otro potencialmente alternativo-, aquí hemos intentando poner en relieve dos aspectos poco explorados. Por un lado, que hay distintas formas de hacer y llegar a la agroecología. Y en ese hacer las relaciones multi-especies son centrales, incluso en un territorio tempranamente occidentalizado como es la región pampeana de Argentina. Por otro lado, las experiencias agroecológicas nos permitieron conocer la configuración del entramado del agropampeano cordobés: si ante la hegemonía de la agricultura convencional deben resistir para existir, reconvertirse y entrar en la agroecología les permite crear existencias diversas en la ruralidad pampeana. Intentamos mostrar que, en el hacer cotidiano y al ras del territorio, las relaciones que 
establecen con la agricultura convencional no son sólo de oposición. Identificamos que resistir se constituye a través de una variedad de acciones y relaciones - de vecindad, negociación, tolerancia, dependencia, indiferencia, entre otras-, que hacen a la estructura de posibilidades de estas experiencias. En ese sentido, uno de los aportes de este trabajo consiste en problematizar y expandir los sentidos asociados a una noción que está recibiendo creciente atención: la(s) agroecología(s).

Córdoba, 10 de octubre de 2020

\section{Bibliografía}

Altieri, M. A. (1987). Agroecology: The Scientific Basis Of Alternative Agriculture. Westview Press.

Altieri, M. A. (2015). Breve reseña sobre los orígenes y evolución de la Agroecología en América Latina. Agroecología, 10(2), 7-8.

Archetti, E., \& Stölen, K. A. (1975). Explotación familiar y acumulación de capital en el campo argentino. Siglo $\mathrm{XXI}$.

Arqueros, M. X., Gallardo Araya, N. L., \& Souza Casadinho, J. (2014). Huertas urbanas agroecológicas: Espacios de acción y reflexión (edición propia).

Barchuk, A., Suez, L. S., \& Locati, L. (2017). Cobertura y uso de la tierra en el área periurbana de la ciudad de Córdoba, Argentina. Aportes a la planificación territorial. Revista de la Asociación Argentina de Ecología de Paisajes, 7(1), 15-30.

Carrizo, C., \& Berger, M. (2013). Justicia Ambiental. El trabajo interdisciplinario en agrotóxicos y transgénicos. Universidad Nacional de Córdoba.

CNA (2019) Censo Nacional Agropecuario 2018. Resultados preliminares. INDEC.

Clastres, P. (2008). La sociedad contra el estado. Terramar.

Dominguez, D. I. (2019). Cartografía de la agroecología y las disputas territoriales en Argentina. Revista Nera, 22(49), 297-313. https://doi.org/10.47946/rnera. v0i49.5886

Dougnac Martínez, G. (2016). Monocultivo sojero, concentración económica, acaparamiento y despojo de tierras: Formas actuales de la expansión del capital en la agricultura argentina. Centro Interdisciplinario de Estudios Agrarios.

FAO. (2018). Transformar la alimentación y la agricultura para alcanzar los ODS. 20 acciones interconectadas para guiar a los encargados de adoptar decisiones. Organización de las Naciones Unidas para la Alimentación y la Agricultura.

Fernández Álvarez, M. I., Gaztañaga, J., \& Quirós, J. (2017). La política como proceso vivo: Diálogos etnográficos y un experimento de encuentro conceptual. Revista Mexicana de Ciencias Políticas y Sociales, 62(231), 277-304.

Giarraca, N., \& Teubal, M. (2008). Del desarrollo agroindustrial a la expansión del «agronegocio»: El caso argentino. En B. Mançano Fernandes (Ed.), Campesinato e agronegócio na América Latina: A questão agrária atual (pp. 139-164). CLACSO.

Goldman, M. (2015). «Quinhentos anos de contato»: Por uma teoria etnográfica da (contra)mestiçagem. Mana, 21(3), 641-659.

Gras, C., \& Hernández, V. (2016). Radiografía del nuevo campo argentino. Del terrateniente al empresario transnacional. Siglo XXI.

Gras, C., \& Sosa, A. (2013). El modelo de agronegocios de las principales megaempresas agropecuarias. En C. Gras \& V. Hernández (Eds.), El agro como negocio: Producción, sociedad y territorios en la globalización (pp. 214-236). Biblos.

Haraway, D. (2016). Staying with the Trouble: Making kin in the Chthulucene. Duke University Press.

Ingold, T. (2015). Desde la complementariedad a la obviación: Sobre la disolución de los límites entre la Antropología social, biológica, arqueología y psicología. Avá. Revista de Antropología, 26, 12-51.

Malinowski, B. (1985). Crimen y costumbre en la sociedad salvaje. Editorial Planeta-De Agostini.

Manildo, L. (2013). La identidad chacarera en las grietas del paisaje sojero. Imago Mundi.

Nogué, J. (1988). El fenómeno neorrural. Agricultura y sociedad, 47, 145-175.

Ottmann, G. S., Renzi, D. G., Miretti, A., \& Spiaggi, E. (2013). Sustainability of Production Practices from an Agro-Ecological Perspective in Two Farms, Santa Fe Province, Argentina. Agroecology and Sustainable Food Systems, 37(4), 430-443.

Palmisano, T. (2018). Las agriculturas alternativas en el contexto del agronegocio. Experiencias en la provincia de Buenos Aires, Argentina. Estudios sociales (Hermosillo, Son.), 28(51), 297-313.

Quirós, J. (2011). El porqué de los que van. Peronistas y 
piqueteros en el Gran Buenos Aires (una antropología de la política vivida). Antropofagia.

Quirós, J. (2014). Neoaluvión zoológico. Avatares políticos de una migración de clase. Cuadernos de antropología social, 39, 9-38.

Sarandón, S., \& Marasas, M. E. (2015). Breve historia de la agroecología en la Argentina: Orígenes, evolución y perspectivas futuras. Agroecología, 10(2),
93-102.

Sarmiento, C. (2018). Evaluación de la sustentabilidad de establecimientos rurales orgánicos [Doctorado en Desarrollo Territorial]. Facultad De Ciencias Económicas, Universidad Nacional De Río Cuarto.

Tsing, A. (2015). Margens Indomáveis: Cogumelos como espécies companheiras. Ilha Revista de Antropologia, 17(1), 177-201. 